\title{
For which patients is maternal oxygen supplementation of value?
}

\author{
Based on the results of a meta-analysis of 16 randomized \\ controlled trials that included peripartum women who \\ received supplemental oxygen $(\mathrm{N}=1,078)$ or room air \\ $(N=974)$, there was no association between \\ maternal oxygen supplementation and a \\ clinically relevant improvement in umbilical \\ artery $\mathrm{pH}$ or other neonatal outcomes.
}

Raghuraman N, Temming LA, Doering MM, et al. Maternal oxygen supplementation compared with room air for intrauterine resuscitation: a systematic review and meta-analysis. JAMA Pediatr. January 4, 2021. doi:10.1001 /jamapediatrics.2020.5351.

\section{EXPERT COMMENTARY}

Michael G. Ross, MD, MPH, is Distinguished Professor of Obstetrics and Gynecology and Public Health, Geffen School of Medicine at UCLA, Fielding School of Public Health at UCLA, Department of Obstetrics and Gynecology, Harbor-UCLA Medical Center, Torrance, California.

Bryan S. Richardson, MD, is Professor Emeritus, Departments of Obstetrics and Gynecology, Physiology and Pharmacology, and Pediatrics, University of Western Ontario Schulich School of Medicine and Dentistry, London, Ontario, Canada.

$\mathrm{M}$ aternal oxygen supplementation is widely used in labor for nonreassuring fetal heart rate (FHR) tracings, although its efficacy is uncertain for preventing fetal acidosis, operative intervention, or sequelae of neonatal encephalopathy. Recently, Raghuraman and colleagues reported the results of a systematic review and meta-analysis that included 16 randomized controlled trials. A total of 1,078 women

The authors report no financial relationships relevant to this article.

doi: 10.12788/obgm.0072 were included in the oxygen group and 974 in the room air group. The primary outcome was umbilical artery $\mathrm{pH} ; 14$ trials reported on this outcome.

After analyzing the pooled and stratified results of the effect of maternal oxygen supplementation versus room air on umbilical artery gas measures, the authors concluded that peripartum oxygen supplementation is not associated with clinically relevant improvement in umbilical artery $\mathrm{pH}$. They acknowledged, however, that the published studies were heterogeneous, lacked data on the association of oxygen supplementation with neonatal outcome, and did not assess oxygen use for abnormal FHR tracings, except for one trial with category II FHR tracings.

\section{Effects of $\mathrm{O}_{2}$ supplementation}

As maternal arterial hemoglobin is nearly saturated under normal conditions, maternal hyperoxia produces only modest increases in umbilical vein $\mathrm{PO}_{2}$ and $\mathrm{O}_{2}$ content during maternal normoxemia but greater effects during maternal hypoxemia (FIGURE). ${ }^{1}$ Maternal $\mathrm{O}_{2}$ supplementation will impact fetal oxygenation depending on the extent of $\mathrm{O}_{2}$ supplementation and the normality of maternal, placental, and fetal $\mathrm{O}_{2}$ transport steps. ${ }^{2}$

Fetal hypoxemia and acidosis can result from an interruption or an impairment of the mother-to-placenta-to-fetus oxygen pathway. $\overline{\text { FAST }}$

TRACK

Fetal hypoxemia and acidosis can result from an interruption or an impairment of the mother-toplacenta-to-fetus oxygen pathway 


\section{FAST}

TRACK

\section{Recurrent late} decelerations occur in less than $2 \%$ of low-risk patients in labor, and severe levels of acidosis occur in only $1 \%-2 \%$ of near-term or term deliveries

\section{FIGURE Effect of maternal $\mathrm{O}_{2}$ supplementation on umbilical vein oxygen content in response to maternal hypoxemia ${ }^{1}$}

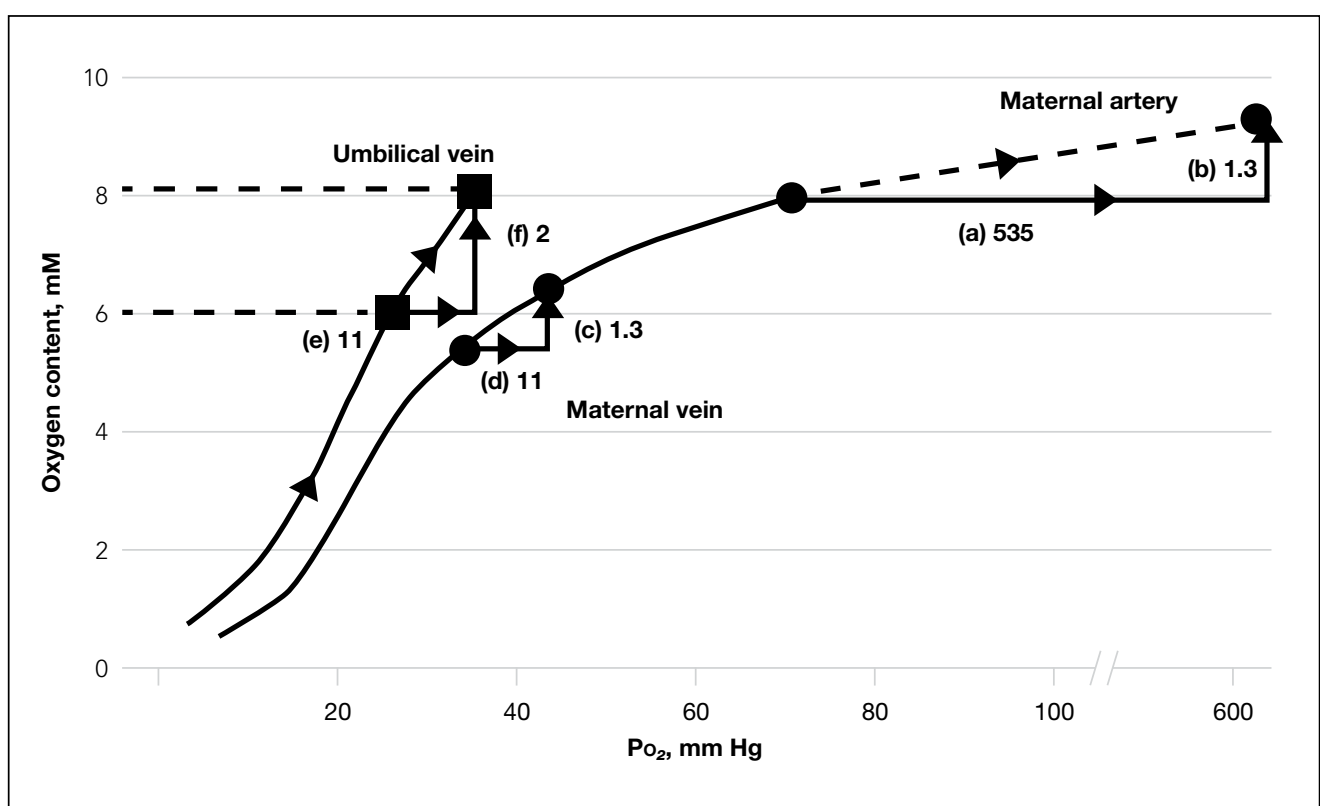

Oxygen results in an increase in (a) maternal arterial $\mathrm{PO}_{2}$; (b) maternal arterial $\mathrm{O}_{2}$ content; (c) maternal venous $\mathrm{O}_{2}$ content; (d) maternal venous $\mathrm{PO}_{2} ;$ (e) umbilical vein $\mathrm{PO}_{2} ;$ (f) umbilical vein $\mathrm{O}_{2}$ content.

With some interruptions of the oxygen pathway, such as placental abruption and complete cord occlusion-induced bradycardia, there would be less impact of maternal hyperoxia. By contrast, with other oxygen pathway impairments, such as reduced oxygen transfer with placental insufficiency, maternal hyperoxia can be of greater value by increasing maternal uterine artery and vein $\mathrm{PO}_{2}$ and, thus, the placental $\mathrm{O}_{2}$ transfer.

\section{Circumstances that may benefit from $\mathrm{O}_{2}$ supplementation}

Late FHR decelerations reflect impairment of oxygen transfer and thus represent the heart rate pattern that is most likely to benefit from maternal hyperoxia. However, recurrent late decelerations occur in less than $2 \%$ of lowrisk patients in labor, ${ }^{3}$ and severe levels of acidosis (umbilical artery $\mathrm{pH}<7.0$ or base deficit $[\mathrm{BD}] \geq 12 \mathrm{mmol} / \mathrm{L}$ ) occur in only $1 \%$ to $2 \%$ of near-term or term deliveries. ${ }^{4,5}$

Variable decelerations also reflect fetal hypoxia and are much more common than late decelerations, so they also may benefit from $\mathrm{O}_{2}$ supplementation. Regardless, $\mathrm{O}_{2}$ supplementation should be seen only as a temporizing strategy while other resuscitative actions are initiated, including preparation for operative delivery, if indicated.

In a prior study by Raghuraman and colleagues ( 1 of only 4 studies that met selection criteria of oxygen supplementation for patients in labor), newborns of patients not receiving oxygen demonstrated $95 \%$ confidence limits of umbilical artery $\mathrm{pH}$ (7.247.28) and BD (2.9-4.3) well within the normal range. ${ }^{6}$ Thus, the low prevalence of cases in which a benefit might be anticipated and the low incidence of severe acidosis challenges the design of prospective studies to detect statistically and clinically significant changes in blood gas measures and newborn outcomes.

The normal mild fetal acidosis that develops during labor is likely a result of recurrent interruption of uterine placental blood flow during uterine contractions ${ }^{7}$ and is unlikely to benefit from maternal 
hyperoxia. Similarly, as placental oxygen transfer is predominantly flow rather than diffusion limited, ${ }^{8}$ oxygen supplementation is unlikely to improve severe variable FHR decelerations. Thus, a randomized study of hyperoxia in unselected laboring patients is unlikely to have a measurable effect on clinically significant acidosis.

\section{Oxygen transport pathway guides treatment}

For the present, an understanding of oxygen transport can guide clinical oxygen use. Thus, mothers with relative hypoxemia will unquestionably benefit with supplemental oxygen administration. Similarly, fetuses at risk for placental dysfunction (for example, growth restriction, postterm) and particularly those manifesting evidence of impaired oxygen transport (that is, late decelerations) may be most likely to benefit from the increased $\mathrm{O}_{2}$ gradient. For patients with

\section{WHAT THIS EVIDENCE MEANS FOR PRACTICE}

In view of the lack of demonstrated adverse effects of maternal supplemental oxygen, clinicians should not hesitate to use it. However, clinicians should recognize that supplemental oxygen is likely to be of value only in patients with significant impairment in the oxygen pathway, and they should choose additional intrauterine resuscitative measures focused on the etiology.

MICHAEL G. ROSS, MD, MPH, AND BRYAN S. RICHARDSON, MD

reduced maternal uterine perfusion (such as hypotension or hypovolemia), pressors and/ or fluid volume are likely to be more effective, while amnioinfusion is of greater value for umbilical cord compression patterns. A reduction in uterine activity may be of benefit to all fetuses exhibiting compromise. Due to the modest impact on fetal oxygen content, maternal hyperoxia does not produce significant fetal oxidative stress as measured by fetal malondialdehyde levels.

References

1. McNanley $\mathrm{T}$, Woods J. Placental physiology. Glob Libr Women's Med. (ISSN: 1756-2228). 2008. doi: 10.3843 /GLOWM.10195.

2. Richardson BS. Fetal adaptive responses to asphyxia. Clin Perinatol. 1989;16:595-611.

3. Sameshima H, IkenoueT. Predictive value of late decelerations of fetal acidemia in unselective low-risk pregnancies. $\mathrm{Am} \mathrm{J}$ Perinatol. 2005;22:19-23.

4. Yeh P, Emary K, Impey L. The relationship between umbilical cord arterial $\mathrm{pH}$ and serious adverse neonatal outcome: analysis of 51,519 consecutive validated samples. BJOG. 2012;119:824-831.

5. Kelly R, Ramaiah SM, Sheridan H, et al. Dose-dependent

relationship between acidosis at birth and likelihood of death or cerebral palsy. Arch Dis Child Fetal Neonatal Ed. 2018;103:F567-F572.

6. Raghuraman N, Wan L, Temming LA, et al. Effect of oxygen vs room air on intrauterine fetal resuscitation: a randomized noninferiority clinical trial. JAMA Pediatr. 2018;172:818-823.

7. Ramsey EM, Corner JW Jr, Donner MW. Serial and cineradioangiographic visualization of maternal circulation in the primate (hemochorial) placenta. Am J Obstet Gynecol. 1963;86:213-225.

8. Nye GA, Ingram E, Johnstone ED, et al. Human placental oxygenation in late gestation: experimental and theoretical approaches. J Physiol. 2018;596:5523-5534. 